\title{
Civil Society Engagement Plan for the Afghanistan National Development Strategy (ANDS)
}

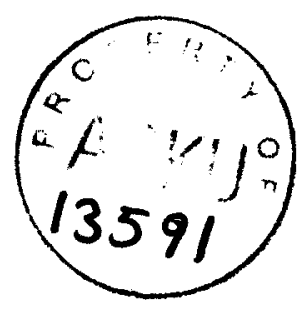

Kabul, December 19, 2005

Civil Society Afghanistan National Development Strategy (CSANDS) Group

Disclaimer:

The paper was prepared under the overall guidance of CSANDS and the views expressed in this document do not necessarily reflect the views of wider Afghan civil society. 


\section{Introduction}

The Afghan National Development Strategy (ANDS) presents a historic opportunity for the people of Afghanistan. As civil society representatives we strongly support this government-led process. The Afghan government's decision to include civil society perspectives in the development of economic policy and the setting of development priorities is a welcome initiative. We also welcome the fact that this decision reflects the government's understanding of civil society's pivotal role in Afghanistan.

The immensity of the challenges confronting the government are encapsulated in the appalling human development indicators that place Afghanistan near the bottom of the Human Development Index. ${ }^{1}$ The formulation of policies to improve this situation requires the active engagement of civil society, in supporting the development of policy and in implementing policy. Civil society engagement will be an important bridge to the Afghan people to create understanding and support for development policy. To this end, civil society organisations can support the development policy of the government and its international partners by ensuring the inclusion of the Afghan peoples' opinions and wishes through conducting participatory and inclusive processes across the country.

This document provides an introduction to the scope of Afghan civil society today and how we plan to engage the widest representation of the Afghan people through both our current and future engagement in the ANDS process:

1. Description of Afghan civil society

2. The role of civil society

3. Civil society and the ANDS

4. An introduction to Civil Society ANDS (CSANDS) group

a. CSANDS structure

b CSANDS mechanism

5. Review of CSANDS engagement with the ANDS

\footnotetext{
I Afghanistan: National Human Development Report 2004: Security with a Human Face, UNDP, Islamabad, Pakistan
} 


\section{Description of Afghan civil society ${ }^{2}$}

At its most inclusive, civil society is simply people and the many ways in which they endeavour to organize, protect themselves and improve their lives. Its diversity reflects human needs and the social, cultural, religious, economic, and political practices formulated to address those needs.

The full spectrum of civil society represents the vast differences found throughout Afghanistan's 34 provinces. The diversity of civil society and structure is particularly great and draws on indigenous quasi-traditional groups as well as more western influenced associations and social groups. Consequently, civil society in Afghanistan extends from groups of micro credit clients to trade associations, from youth groups to tribal elders, and from community councils to nation wide networks.

Civil Society in Afghanistan includes:

- Shuras, jirgas, and community councils

- Religious figures including institutions such as ulamas

- Tribal and qozin structures

- Small entrepreneurs, including sazdagars (tejaar) (traders)

- Voluntary and professional associations, NGOs including humanitarian and development organisations, interest groups (e.g. trade unions), and social and cultural associations

- Advocacy and rights based groups

- Media

As Afghanistan's recent history is chequered with conflict, invasion and large migrations; Afghanistan's civil society has become even more diverse and fragmented. At the same time a developing aspect of civil society is the increasing network of civil society actors spearheaded by consortiums and associations (e.g. ACBAR, ACSA, ACSF, ANCB, AWN, CSANDS, HRRAC, and GCAP3).

In addition to communities and government, Afghan civil society has also been supported for several decades by international civil society. International civil society - consisting of non-government organisations and world-wide associations - works with and alongside Afghan civil society to build capacity, provide services and empower Afghan communities.

\section{The role of civil society 4}

The strength of civil society is that it is rooted within communities and interacts at various different levels of society (see diagram $^{5}$ ). It both represents the diverse

\footnotetext{
${ }^{2}$ The definition given here serves the purposes of the ANDS, as civil society definition may vary in a different context.

${ }^{3}$ Please see appendix for full names of these organisations

${ }^{4}$ As per the definition, the role of the civil society stated here serves the purpose of the ANDS.
} 
interests of the general public to the government and other stakeholders, while also directly interacting with the greater population in its activities. As a result civil society plays a critical role in linking communities and building social cohesion.

\section{Levels of Interaction and Civil Society in Afghanistan}

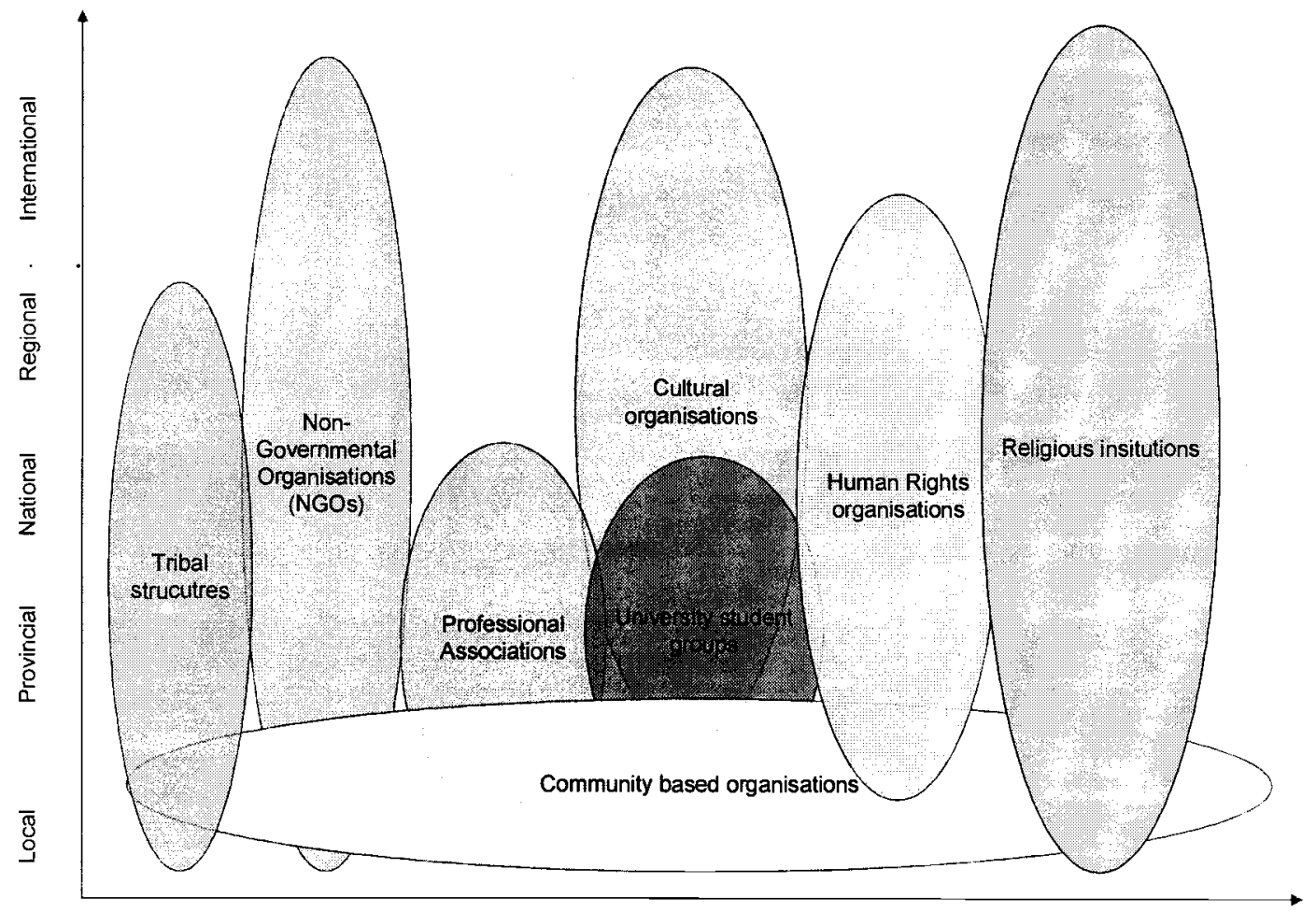

In Afghanistan, civil society plays an extremely important role in social and political development. It provides an essential bridge between the Afghan people, the Government and other stakeholders. Its position affords it unique capacity in supporting and checking the nascent State. Civil society is an essential building block to the democratic process.

With regards to the ANDS process, three main functions of Afghanistan civil society have been identified:

Information flows regard the exchange of information between communities, government and other stakeholders. Information flows are the keys to public awareness, expectation management and enabling public participation. It is also paramount to ensure the government's and other stakeholders' understanding of policy and programming impacts on communities. Information flows include public information, civic education, awareness campaigns, information collection, consultation and advocacy.

\footnotetext{
${ }^{5}$ This diagram is intended to provide a pictorial representation of civil society in Afghanistan, not a definitive representation. It shows how civil society actors interact at different levels.
} 
Services are provided to communities and individuals, and encompass social and economic activities. Direct services to people include access to water and sanitation, education, health, security, social protection, capacity building, vocational training, micro finance, access to market, etc.

Mutual Accountability is the mutual monitoring by the government and civil society of each other's activities. A healthy and vibrant civil society monitors government and other stakeholders' activities (including other civil society actors), analyzes their impacts and effectiveness, and promotes the needs and interests of the greater public.

The World Bank states: "Civil Society Organizations can play an important role in improving government accountability through - greater transparency and social control" 6

\section{Civil Society Roles and Contributions}

\section{Information flows}

No other segment of society can match civil society's ability to reach communities and individuals throughout the country. The most remarkable example is the work of the Afghan Civil Society Forum (ACSF) and its nation-wide network of civil society organizations that have delivered civic education for the Constitution (2003), presidential (2004), parliamentary and provincial elections (2005). During the parliamentary election process ACSF's network reached 11.3 million people in 316 of the 393 districts in Afghanistan.

\section{Serviç̣es}

Afghan civil society, in conjunction with the Government, provides many services throughout the country. Services span the full spectrum of needs and include rural and agricultural development, small infrastructure, water \& sanitation, health, education, micro-finance, natural resource management, community development, peacebuilding and reconciliation, capacity building, and social protection. As an example of a portion of the services provided through civil society organisations, for the period from 2002 to 2005 , the following was achieved:

- 388 clinics supported (treating over 4 million patients)

- 3,092 schools supported (27,462 teachers trained)

- 6,949 kilometres of irrigation system built or repaired

- 7,343 kilometres of tertiary roads built or repaired

- Over 8,500 wells dug

- More than 5.5 million Afghans have received health education

- Approximately 1.5 million people have received food, seeds and tools - 136,212 Afghans have benefited from access to micro-credit schemes

6 World Bank - Civil Society Engagement: Overcoming Barriers, Promoting Synergies, May 2002 
Source: Adapted from ACBAR, "ACBAR Statement for the Afghanistan Development Forum", April 2005 and data from MISFA 30"th September 2005.

\section{Mutual Accountability}

Civil society takes a significant role in monitoring itself and others. Numerous civil society groups have monitoring, policy and advocacy capacities including; ICRC, AIHRC, CPAU, AWN, TLO, ACSF, ANCB, Christian Aid, Action Aid, ACBAR, OXFAM and CARE.

As an example, the Afghan Independent Human Rights Commission (AIHRC) has produced numerous reports, briefs and electoral verifications, under its mandate "to monitor the situation of human rights, where the liberty of people have been denied, restricted or violated in police custody, detention centers, prisons, juvenile prisons and other situations where human rights are vulnerable. The Commission also monitors freedom of speech and the status of women and children." (Source: AIHRC website: http://hunww.ailhrc.org.afD.

Another example comes from four NGO consortiums (ACBAR, ANCB, AWN and SWABAC) and their members, who earlier this year presented the "Code of Conduct for NGOs Engaged in Humanitarian Assistance, Reconstruction and Development in Afghanistan", which sets the standards for transparency, accountability and professionalism to which all of its members are accountable.

(Source $A C B A R$ toebsite: unum.acbar.org)

\section{Civil society and the ANDS}

Following the development framework set out by past key strategic documents including the National Development Framework (2002), and the Securing Afghanistan's Future (2004) - the Government is now working to fill the requirements of a Poverty Reduction Strategy Paper (PRSP), which will formulate a five-year policy plan for promoting growth, generating wealth and reducing poverty and vulnerability. The PRSP is the process through which governments work with both domestic stakeholders, including civil society organizations, as well as international donors to set overall development and poverty-reduction strategies. For Afghanistan the requirements for the PRSP are being met by the Afghanistan National Development Strategy (ANDS).

The ANDS comes at a significant time when the elected President and his government are taking a leading role in setting policies, and when the focus has shifted from humanitarian aid to long-term development. Thus, the outcome of the ANDS will ultimately play a large role in determining the future prosperity, equity and opportunities of Afghan citizens.

Any strategy for development must include the voices of civil society, particularly the poor and marginalized. To this end, Afghan civil society organizations have a critical role in the process of increasing awareness of national policy, participating in policy processes, and monitoring policy outputs and outcomes. 
The World Bank defines participation as:

"The process through which stakeholders influence and share control over priority setting, policy-making, resource allocations and access to public goods and services." 1

It also notes that PRSPs should:

"Be developed transparently with broad participation of elected institutions, stakeholders including civil society, key donors and regional development banks" 2

Source: Oxfam, Oxfam's Guide to the PRSP

1. 'Organising Participatory Processes in the PRSP', S.Tikare, D. Youssef, P.Donnelly-Roark, P.Shah, World Bank, April 2001

2. Development Committee Communiqué, World Bank September 27th, 1999.

\section{Civil society contributions to ANDS}

Civil society participation in the ANDS will include efforts on behalf of individual organizations and associations as well as through various networks and coalitions.

These efforts will include:

Information flow, which will provide information and consultation for the civil general public, civil society and the Government;

Services, such as implementation of programs, capacity building, and research;

Mutual Accountability, as the Government will monitor civil society in the ANDS process, civil society will monitor to ensure full engagement by all civil society actors including the marginalized and poor, policy and budgetary relevance and program effectiveness, sustainability and Afghan ownership.

Key to civil society efforts will be the development of partnerships between both civil society actors (e.g., public and private partnerships) and government departments. Such links will enable both stronger collaboration and coordination, and promote longer term sustainability and efficiency with regards to information flows, service provision and mutual accountability. Stronger government linkages will also empower both agencies and communities to play a greater role in contributing to emerging government policy and rural development plans.

Several specific initiatives have been developed among these activities, and of primary focus for the ANDS process is the creation of the Civil Society ANDS (CSANDS) resource group. The CSANDS group was created to increase and widen civil society participation in the ANDS process and maximize its effectiveness in consultation with the government and other stakeholders. Specifically, the purpose of the CSANDS group is to organise and support civil society consultation, research activities, capacity building, and public education with regards to the ANDS process. Additionally, CSANDS intends to monitor the ANDS development and 
implementation efforts. As of December 2005 over 70 civil society organisations have participated in CSANDS activities. ${ }^{7}$

CSANDS is intended as an inclusive mechanism that will build off of existing structures (e.g., networks and coalitions such as ACBAR, ACSA, ACSF, ANCB, AWN and GCAP) and complement other civil society initiatives. Recent initiatives include the development of the Trade Advocacy Group (a joint effort by the Global Call to Action against Poverty (GCAP) and Afghan traders and producers), and the Kabul Conference (a civil society conference being held in Kabul that will lead into the London Conference). Preliminary discussions are also ongoing revolving a Participatory Poverty Assessment that will be a joint effort with the Government and Civil Society.

\section{Kabul Civil Society Conference}

In .December and January, members of Action for Civil Society in Afghanistan (ACSA) and the Afghan Civil Society Forum (ACSF) will be overseeing a nationwide civil society consultation process. This process will culminate in the Kabul Civil Society Conference on January $16-18$.

The civil society consultation will include individuals conducting surveys and interviews in each of Afghanistan's provinces. This information will be presented and discussed at the Kabul conference - from which a Civil Society Statement will be prepared. Two representatives will be elected to take the Statement and present it at the London Conference.

In addition to being members of CSANDS, ACSA and ACSF will incorporate information gained from CSANDS efforts in designing questionnaires and references for the Civil Society Conference. CSANDS will also build on these provincial consultation efforts in preparation of its provincial strategy during the ANDS process.

\subsection{CSANDS structures}

To organize and carry out its activities, CSANDS employs a secretariat at the national level. Under the CSANDS secretariat, two complementary mechanisms for civil society engagement and consultation have been formed (see diagram on page 9): these include eight working groups formed in line with the original eight pillars of the ANDS, and an eight province consultation structure ${ }^{8}$.

The pillar working groups are assigned to primarily create networks of active organizations and individuals to:

- collect information,

- discuss programs and government plans,

- monitor and analyze priorities, implementation and impact,

- track budgets and

\footnotetext{
${ }^{7}$ Please see Appendix for a full list of active members of CSANDS

${ }^{8}$ CSANDS will strive to adapt to changes in the Government Pillar structure
} 
- advocate on behalf of their concerns.

To maximise the reach of the ANDS process during Solar Year 1385 (2006), CSANDS will set up provincial structures in eight regions of Afghanistan. These provincial focal points will organize CSANDS activities related to capacity building, awareness raising, consultation, feedback and monitoring. They will both benefit from and contribute to the pillars working groups. They will be led by Provincial Consultation Officers who will be supported by associated civil society organizations.

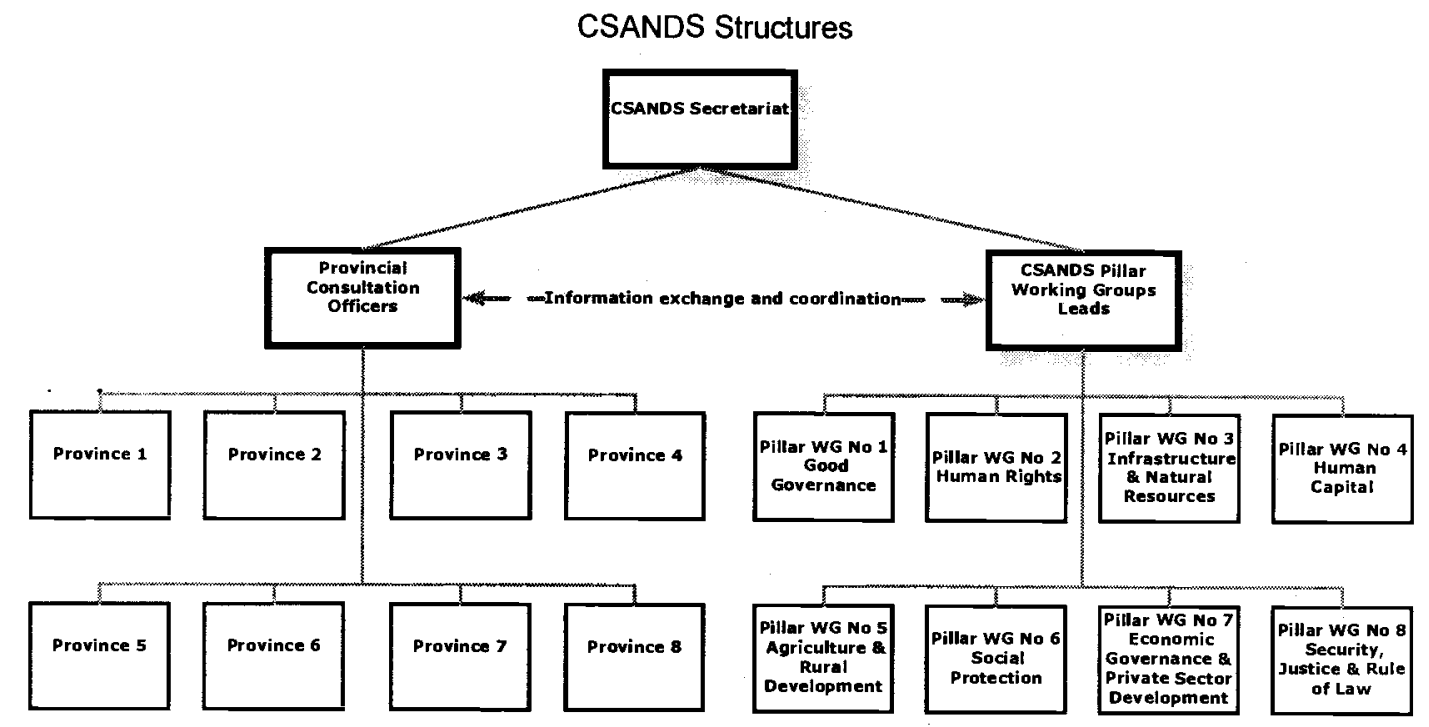

\subsection{CSANDS mechanism for engagement with the ANDS}

CSANDS activities will take part within the structures outlined above in the provinces and pillar working groups through the lens of information flow, service and mutual accountability. The activities will complement each other and develop a constructive process that will inform decision-makers and policy while empowering communities.

In terms of information flows, CSANDS will concentrate on awareness raising on issues linked to the ANDS. This is a crucial step in ensuring that civil society is able to adequately respond to the process.

By way of services, CSANDS will undertake research and capacity building activities. Firstly, research will be conducted through a national consultation process with different civil society actors. Secondly, capacity building for civil society organisations (CSOs) during 2006 will include training on numerous issues such as: needs assessments, budget tracking, policy analysis and advocacy.

Regarding accountability, CSANDS and its members will monitor the engagement by all stakeholders. Specifically, CSANDS will monitor policy and fiscal issues emanating from the ANDS process. In addition to which, CSANDS will ensure that policies will benefit the poor and marginalised. 
CSANDS and its members, informed by civil society engagement, research and analysis, will consult with government and other stakeholders to share and compare lessons in order that Afghanistan can take full advantage and move forward. Outputs will include:

- Active engagement in the ANDS Pillar Working Groups

- Policy papers, assessments, and evaluations of ANDS and other government policies and their impacts

- Information sharing through regular meetings, workshops, training, websites

\section{Review of CSANDS engagement with the ANDS}

During October and November 2005 initial CSANDS Pillar Working Groups consultations were held with some 70 CSOs which collected comments on their experiences throughout Afghanistan.9 The consultations consisted of seminars, workshops, questionnaires and focus group discussions. The information that was collected from these Working Groups was compiled and will form the basis of future engagement of civil society and policy engagement during the ANDS consultation phase.

The following table summarises the roles (information flows, services, mutual accountability) and the issues of concern highlighted by the CSANDS Pillar Working Groups. However, given the complexity of civil society, the cross cutting themes (i.e. gender, counter-narcotics, human rights) and the connectivity between the pillars this preliminary table is not exhaustive or all encompassing.

\footnotetext{
${ }^{9}$ Please see Appendix for a full list of CSOs involved in the consultations.
} 


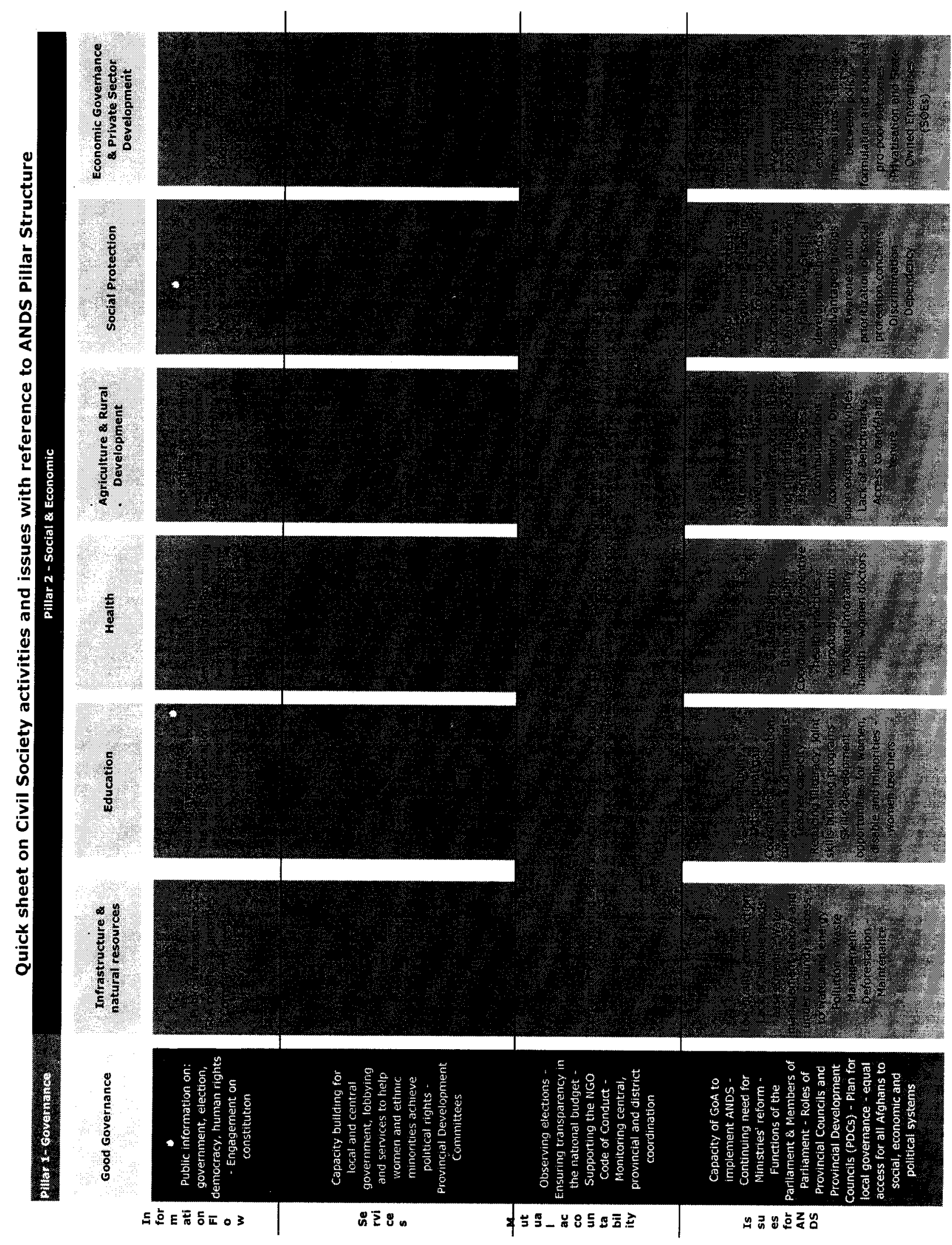




\section{Appendix}

List of organizations so far participating in the CSANDS group:

1. ActionAid Afghanistan

2. Afghan Civil Society Association (ACSA)

3. Afghan Civil Society Forurn (ACSF)

4. Afghan Disables Reconstruction Association (Qandahar)

5. Afghan Handicrafts Industries Association

6. Afghan Health and Development Services (AHDS)

7. Afghan Independent Human Rights Commission (AIHRC)

8. Afghan Institute of Learning (AIL)

9. Afghan National Association for Blinds

10. Afghan NGO's Coordination Bureau (ANCB)

11. Afghan Organization of Human Rights and Environmental Protection (AOHREP)

12. Afghan Women Network (AWN)

13. Afghan Women's Educational Centre (AWEC)

14. Afghan Women's Skills and Development Center (AWSDC)

15. Afghan Women's Social and Cultural Organization (AWSCO)

16. Afghanaid (AAD)

17. Afghanistan Association of the Blind $(\mathrm{AAB})$

18. Afghanistan Development Association (ADA)

19. Afghanistan NGO Safety Office (ANSO)

20. Afghanistan

Rehabilitation and Reconstruction Agency Falah (ARRAF)
21. (TLO)

21. Urgence -

Réhabilitation -

Développement (URD)

22. Women and Children Legal Research Foundation (WCLRF)

World Council of Credit Unions, Inc. (WOCCU)

23. for Afghan Women (HDCAW)

24. Heart of Asia Council

25. Human Rights Research and Advocacy Consortium (HRRAC)

26. International Medical Corps (IMC)

27. International Rescue Committee (IRC)

28. Kabul University.

29. Kanon-e Tafahom

30. $\mathrm{KOO}$

31. Medair

32. Microfinance Investment Support Facility Afghanistan (MISFA)

33. Mission d'Aide au Developpement des Economies Rurales en Afghanistan (MADERA)

34. National Disables Association

35. National Unit of Disables

36. Noor Education Centre (NEC)

37. Norwegian Church Aid (NCA)

38. Norwegian Project Office (NPO)

39. OLC

40. On the Frontier (OTF)

41. Oxfam

42. Rural Rehabilitation Association for Afghanistan (RRAA)

43. Salsal Foundation Sanayee Development
44. Foundation (SDF)

45. Sandy Gall's Afghanistan Appeal (SGAA)

46. Save the Children

47. Shahamat Health and Rehabilitation Organization (SHRO)

48. Solidarité Afghanistan Belgium (SAB)

49. Solidarités

50. STARS

51. Terre des Hommes (TDH)

Tribal Liaison Office

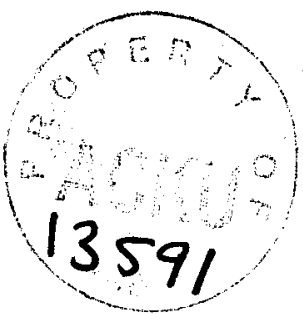

